American Journal of Environmental Sciences 3 (4): 241-246, 2007

ISSN 1553-345X

(C) 2007 Science Publications

\title{
Evaluation of Sorghum Density As Affected By Two Water Qualities Under Drip Irrigation System
}

\author{
${ }^{1}$ Ould Ahmed B.A, ${ }^{1}$ Yamamoto T., ${ }^{1}$ Inoue M. ${ }^{2}$ Dehghanisanij H. \\ ${ }^{1}$ Tottori University, Arid Land Research Center. 1390 Hamasaka, Tottori 680-0001, Japan \\ ${ }^{2}$ Agricultural Engineering Research Institute, Karaj, Iran, P.O.Box: 31585-845
}

\begin{abstract}
Pot experiment was conducted under glasshouse conditions during 2005 at the Arid Land Research Center, Tottori University in Tottori, Japan. The study presented here was aimed to evaluating the response of sorghum (Sorghum bicolor (L) Moench), density under two different water qualities. The investigation was carried out in randomized complete block design experiments located in a plastic greenhouse. Crop growth was temporal varied with crop density and water quality. The statistical parameters; mean, median, $\mathrm{CV}$, and the PCV, for the time series LWP data indicated the impact of sorghum density and water quality, on osmotic stress was best discriminated by PCV, followed by CV, median, and mean. The impact of different sorghum density on stresses under good water quality was similar trend to the impact of salinity under low density. The time series analysis for LWP indicated that PCV best statistical parameter to discriminate the impacts of stress under different water quality. The grain yield was significantly influenced by plant density regardless of water quality. Electrical conductivity was also affected by water quality as well as by plant density.
\end{abstract}

Key Words: leaf water potential, osmotic stress, saline water, Sorghum, top water

\section{INTRODUCTION}

Dwindling supplies of quality water for irrigation and competition from other users are forcing farmers to use poor quality water, more specifically high in salinity or saline irrigation water, particularly in developing countries ${ }^{[22,18,2,17,1]}$. Several workers (Fisher, ${ }^{[3]}$; Shani and Dudle ${ }^{[22]}$ Giedoen et al. ${ }^{[5]}$; Katerji et al. ${ }^{[9]}$ and Katerji et al. ${ }^{[7]}$ ) have reported that when saline water is used for irrigation due attention should be given to minimize root-zone salinity through appropriate management practices, including leaching. Regardless of the approaches undertaken, a good understanding of how these changes in management practices are reflected in available soil water, soil water salinity, and osmotic status of crop, is important.

In the Mauritanian semi-arid regions sorghum, which occupies $60 \%$ of the total area under grain production, is a dryland crop grown mostly in the arid to semi-arid regions. Sorghum is widely used for human consumption and as feed and fodder ${ }^{[11]}$. Josserand and Silva ${ }^{[6]}$ reported that sorghum in Mauritania accounts for $25 \%$ of the total grain production. Farmers frequently face crop failure due to drought, but supplementary or full irrigation for this crop has never been tried out. This may be partially due to insufficient water resources other than groundwater, which is primarily used for human and livestock consumption. The wells are usually 5 to $20 \mathrm{~m}$ deep and the dry-out during consecutive dry years. The groundwater tends to become saline after years of water extraction. Under such circumstances, people abandon saline wells and move to new wells.

Irrigation is usually gravity fed and the water application efficiency is very low. The needs for introduction of new irrigation systems and improvements in existing practices, at least in the intensive vegetable producing regions, have been identified. The drip irrigation is the most efficient system in delivering just the required amount of water directly in the crop root-zone ${ }^{[20]}$. The use of such system is particularly important where limited water resources, including saline groundwater, are used for irrigation. However, the coast of installation and maintenance and the technical skills required for its operation are high for a country like Mauritania. Nevertheless, for future planning purposes at least some limited background information about appropriate management practices is required for saline water irrigation in drip systems ${ }^{[1,14,4]}$ to sustain productivity and soil resource utilization in this country.

Leaf water potential (LWP) has been widely used as an indicator of osmotic stress status of crops ${ }^{[22,11,8]}$. The information with regard to temporal dynamics of this indicator as impacted by management variables is important to fine tune management options, particularly for sandy soils, mostly present in arid and semi-arid regions, and are characterized by low water holding,

Corresponding Author: Ould Ahmed Bouya Ahmed, 1390 Hamasaka, Arid Land Research Center, Tottori University Tel: +81-857-23-3411, Fax: +81-857-29-6199 
poor retention, rapid infiltration and high percolation losses.

In the absence of systems variables impact, the statistical parameters; mean, median, percentile values (PCV), and coefficient of variation, $\mathrm{CV}$ have been widely used to characterise temporal dynamics of a given data as impacted by input variable $[15,23,24]$. However, the discriminating ability of the aforementioned parameters might vary with the type of time series data. The objective of this study was to assess the abilities of the statistical parameters; mean, median, $\mathrm{PCV}$, and $\mathrm{CV}$, to discriminate the impact of water quality irrigation management options; two water irrigation qualities and four sorghum densities levels, on the stress indicator LWP.

Sorghum density was discussed by several authors (Watkinson et al., ${ }^{[25]}$; Rees, ${ }^{[16]}$; Santos et al. ${ }^{[19]}$ ). However, there is lack of data about sorghum density under saline drip irrigation.

The objective of this study to evaluate the impact of sorghum plant density under two different water quality using drip irrigation system.

\section{MATERIALS AND METHODS}

Experiment: The experiment was conducted at the Arid Land Research Center, Tottori University (Tottori; $35^{\circ} 32^{\prime} \mathrm{N}$ and $134^{\circ} 13^{\prime} \mathrm{E}$, Japan) during 2005 growing seasons, April to August, in a plastic greenhouse. This greenhouse prevented only rainfall into the experimental plot, while the other climatic variables were similar to the outside environment. The soil at the experimental site is sandy consisting $95 \%$ sand, $1.3 \%$ silt and $3.7 \%$ clay. The water holding capacity is 0.05 $\mathrm{cm}^{3} \mathrm{~cm}^{-3}\left(0.03-0.08 \mathrm{~cm}^{3} \mathrm{~cm}^{-3}\right)$. All the pots were installed in the same level of soil surface. Drainage water was collect by using small pipe was connected between experiment pot and small covered pan was installed in the $30 \mathrm{~cm}$ beneath. During the irrigation season four crop densities using pot with four replicates was used. In each replicate pot (diameter $0.30 \mathrm{~m}$ and height $0.6 \mathrm{~m}$ ), the sub-main pipe of the drip irrigation system (DIS) was divided into three lateral lines and on each line there were 4 emitters that were $60 \mathrm{~cm}$ apart and each emitter irrigated one pot. The DIS was operated at $0.1 \mathrm{MPa}$ to achieve an emitter discharge of $2 \mathrm{~L} \mathrm{~h}^{-1}$. Fertilizer was applied uniformly to each pot when the soil was plowed $\left(180 \mathrm{~kg} \mathrm{~h}^{-1} \mathrm{~N}, 45 \mathrm{~kg} \mathrm{~h}^{-1} \mathrm{P}, 80\right.$ $\mathrm{kg} \mathrm{h}^{-1} \mathrm{~K}$ ). At the end of experiment the grain yield for each plot were determined.

During the growing season the treatments consisted of two irrigation water level. The water irrigation applied was top water $\left(0.11 \mathrm{dS} \mathrm{m}^{-1}\right)$ and saline water $\left(5.40 \mathrm{dS} \mathrm{m}^{-1}\right)$. Irrigation input was equivalent to $100 \%$ of daily open-pan evaporation, which was measured in the greenhouse applied daily. For details of the computation pertaining to this particular greenhouse conditions please see Ould Ahmed et al. (2006 and 2007). The total top water and saline water input was 760 and $725 \mathrm{~mm}$, respectively for each pot.

\section{RESULTS AND DISCUSSION}

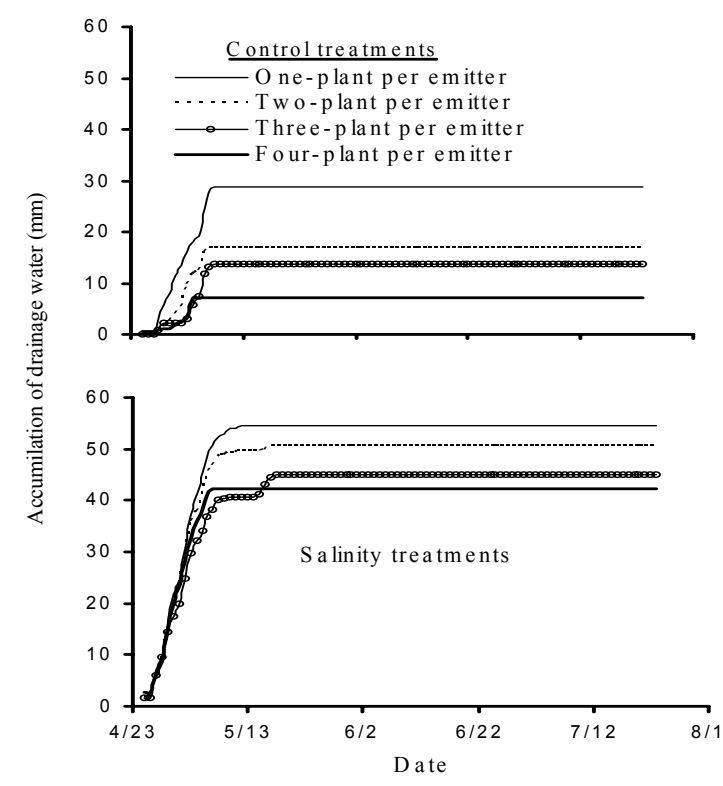

Fig. 1: Accumulations of drainage water from different sorghum plants densities and two water qualities.

Accumulative drainage water as affected by sorghum density: Figure 1 show temporal variation of drainage water as affected by different sorghum density and water quality. The data indicated that the amount of water was less under higher density (three, and fourplant per emitter) compared to low densities (one and two-plant per emitter) regardless of water qualities. Statistical analysis show significant differences between treatment under top water and saline water. However, the accumulative amount of drainage water was almost double under saline irrigation. Thus, could be attributed to osmotic pressure where the plant cannot observe water under saline condition.

Data of electrical conductivity of drainage water (ECd) was impacted by sorghum density, particularly under saline water irrigation. The result showed there was no significant difference between treatments under top water, (Fig. 2). Though, there were differences in the ranges in ECd of the treatments under saline water irrigation, the mean \pm sd indicate higher significant 
difference among thus treatments (Fig. 2). The highest ECd was observed in the higher density under saline water (four-plant per emitter) $7.31 \pm 1.5 \mathrm{dS} \mathrm{m}^{-1}$ followed by three-plant per emitter was $5.70 \pm 1.1 \mathrm{dS} \mathrm{m}^{-1}$; twoplant per plot was $4.10 \pm 1.2 \mathrm{dS} \mathrm{m}^{-1}$, and one-plant per emitter was $2.7 \pm 0.9 \mathrm{dS} \mathrm{m}^{-1}$.

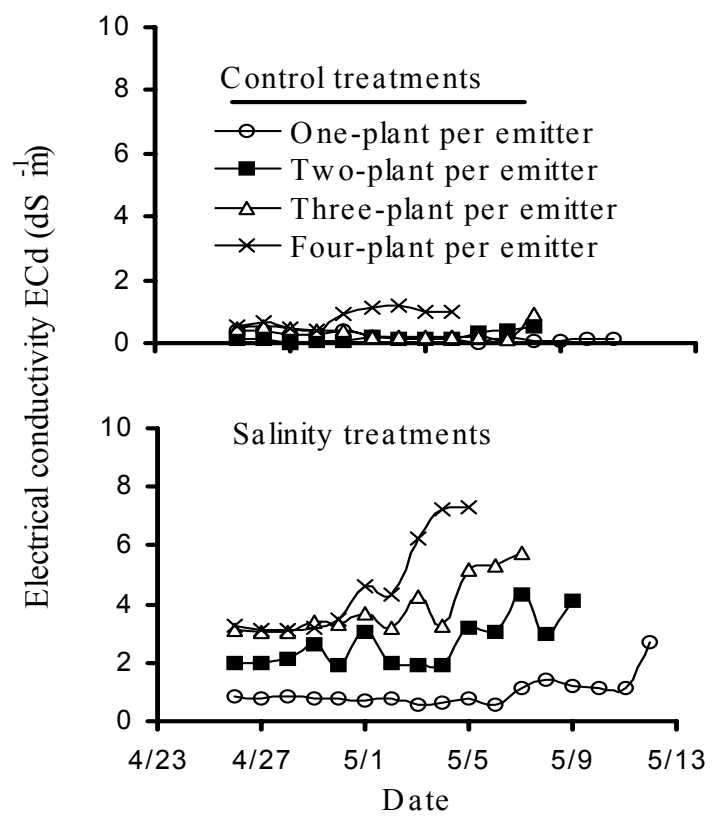

Fig. 2: Electrical conductivity of drainage water during the experiment period

Grain yield and electrical conductivity in the end of the experiment: The yield data are presented in the Fig. 3. Thought, the grain yield was affected by water quality as well as by crop density. However, the highest grain yield was observed in lower density (one-plant and two-plant per emitter) under top water 0.030 and $0.031 \mathrm{~kg}$ /plant, respectively compared with 0.027 and 0.019 for higher density (three-plant and four plant per emitter), respectively. Data indicated that there were no significant differences between low density treatments. In general the grain yield under saline treatment was less than the treatments under top water, thought the decreasing trend was similar. Implying that crop was subject to water stress in case of top water due to high crop density, while that under saline water treatment subjected to salinity stress. The grain yield for oneplant treatment was $0.023 \mathrm{~kg}$ /plant compared to 0.022 , 0.021 , and $0.013 \mathrm{~kg} / \mathrm{plant}$, for two-plant, three-plant, and four-plant per emitter, respectively.

Soil water electrical conductivity (ECsw) was very low under top water and data showed not significant differences among treatments. Therefore, the ECsw was increased with increasing density of crop. The data clearly showed significant differences among treatments. The highest ECsw was observed in fourplant per emitter was $38 \mathrm{dSm}^{-1}$ Compared with 14,16 , and $22 \mathrm{dSm}^{-1}$ for one-plant, two-plant, and three-plant per emitter, respectively (Fig. 4).

\section{Discriminating the impact of different crop density using LWP as a stress indicator:}

The temporal data for LWP (absolute values) indicate an increasing trend with time, exclusive of that in the control, and it increased with increasing salinity (data not shown). There was a rapid increase in LWP initially with time and thereafter there was a slow increasing and fluctuating trend. The LWP in the lower density (one and two-plat per emitter) are less than the threshold value of $-1.5 \mathrm{MPa}^{[10]}$ throughout the growing, suggesting any impact through low-density under top water on sorghum yield would be small or insignificant. It should however be noted the LWP in under top water was always less than the salinity treatments. The number of osmotic stress days, defined by the threshold value, during crop growth stage in the one-plant per emitter was 0 compared with 4,17 , and 37 days for two-plant, three-plant, and four-plant per emitter, respectively (Table 1). While the osmotic stress under saline water treatment during the crop stage I the oneplant per emitter was 0compared with 35, 47, and 51 days for for two-plant, three-plant, and four-plant per emitter, respectively. The LWP reflects water/osmotic stress status in plant leaves, thus we suggest the leaf osmotic stress increased with increasing crop density, because, the increasing osmotic stress trend was almost same regardless of water quality of irrigation.

The impact of sorghum density, in a given water quality, was discriminated by mean \pm sd of LWP, (Table 2). The median and PC20 values for LWP were able to discriminate the impact of sorghum density was characterized higher values of median and PC20 regardless of water quality. Compared with means, it seems a consistent trend

The mean \pm sd of LWP for different salinity levels indicate significant difference between top water and saline water irrigation. For median and PC20 the absolute values increased with increasing sorghum density, similar trend was observed for CV.

A comparison of the performance of time series statistical parameters ${ }^{[15,23,24}$; mean, median, $\mathrm{PC} 20$, and $\mathrm{CV}$ in their discriminating ability of irrigation management treatments impacts, our analysis indicate the PC20 outperformed the others, followed by Median, $\mathrm{CV}$, and mean. We prefer the use PC20, because it indicates that indicates that $80 \%$ of time the stress is less than a given value and this has the advantage of being easily understood by producers. 
Table 1: Number of stress days during the growing season and critical crop growth stage as determined by leaf water potential (LWP) under two different water qualities and four sorghum plant densities.

\begin{tabular}{|c|c|c|c|c|}
\hline \multirow[t]{4}{*}{ Water quality } & \multicolumn{4}{|c|}{ Treatments } \\
\hline & \multicolumn{4}{|c|}{ Number of days during which LWP $>-1.5 \mathrm{MPa}$ threshold } \\
\hline & One-plant & Two-plant & Three-plant & Four-plant \\
\hline & Per emitter & Per emitter & per emitter & per emitter \\
\hline \multicolumn{5}{|l|}{ Top water } \\
\hline$\left(0.11 \mathrm{dS} \mathrm{m}^{-1}\right)$ & 0 & 4 & 17 & 37 \\
\hline \multicolumn{5}{|l|}{ Saline water } \\
\hline$\left(5.40 \mathrm{dS} \mathrm{m}^{-1}\right)$ & 0 & 35 & 47 & 51 \\
\hline
\end{tabular}

Table 2: The sensitivity of the time series statistical parameters; mean, median, the percentile value (PC20) and coefficient of variation (CV), for leaf water potential as impacted by two water qualities and four sorghum plant densities.

\begin{tabular}{|c|c|c|c|c|c|}
\hline \multicolumn{6}{|c|}{ Time series statistical parameters } \\
\hline Treatment & Range & Mean & Median & PC20* & $\mathrm{CV}$ \\
\hline \multicolumn{6}{|c|}{ Leaf water potential } \\
\hline \multicolumn{6}{|l|}{ Top water } \\
\hline One-plant per emitter & $-0.8--0.2$ & $-0.46 \pm 0.16$ & -0.4 & -0.6 & 0.87 \\
\hline Two-plant per emitter & $-0.8--0.3$ & $-0.6 \pm 0.30$ & -0.5 & -0.6 & 0.63 \\
\hline Three-plant per emitter & $-1.2--0.6$ & $-1.0 \pm 0.48$ & -0.8 & -1.1 & 0.42 \\
\hline Four-plant per emitter & $-1.6--0.8$ & $-1.4 \pm 0.51$ & -1.3 & -1.5 & 0.21 \\
\hline \multicolumn{6}{|l|}{ Saline water } \\
\hline One-plant per emitter & $-1.1--0.6$ & $-0.8 \pm 0.21$ & -0.8 & -0.9 & 0.54 \\
\hline Two-plant per emitter & $-1.7--0.9$ & $-1.32 \pm 0.23$ & -1.5 & -1.7 & 0.44 \\
\hline Three-plant per emitter & $-2.7--1.0$ & $-1.84 \pm 0.29$ & -1.9 & -2.2 & 0.21 \\
\hline Four-plant per emitter & $-2.9--1.2$ & $-2.21 \pm 0.32$ & -2.4 & -2.6 & 0.17 \\
\hline
\end{tabular}

The median and PC20 values for LWP were able to discriminate the impact of sorghum density was characterized higher values of median and PC20 regardless of water quality. Compared with means, it seems a consistent trend

The mean \pm sd of LWP for different salinity levels indicate significant difference between top water and saline water irrigation. For median and PC20 the absolute values increased with increasing sorghum density, similar trend was observed for CV.

A comparison of the performance of time series statistical parameters ${ }^{[15,23,24}$; mean, median, PC20, and $\mathrm{CV}$ in their discriminating ability of irrigation management treatments impacts, our analysis indicate the PC20 outperformed the others, followed by Median, $\mathrm{CV}$, and mean. We prefer the use PC20, because it indicates that indicates that $80 \%$ of time the stress is less than a given value and this has the advantage of being easily understood by producers.

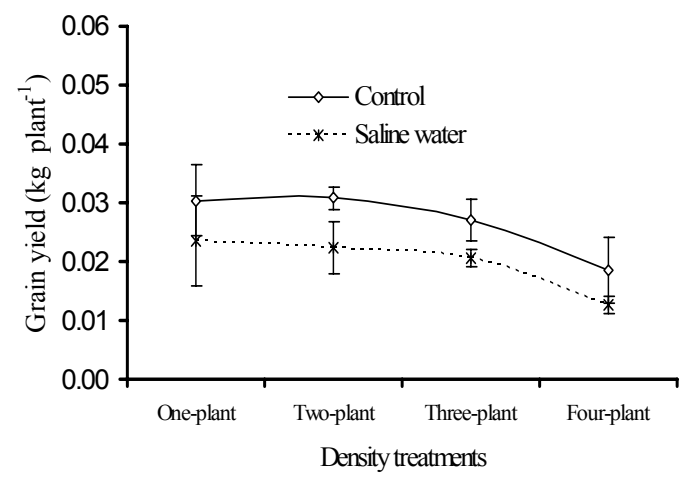

Fig. 3: Sorghum yield of different densities under two water qualities 


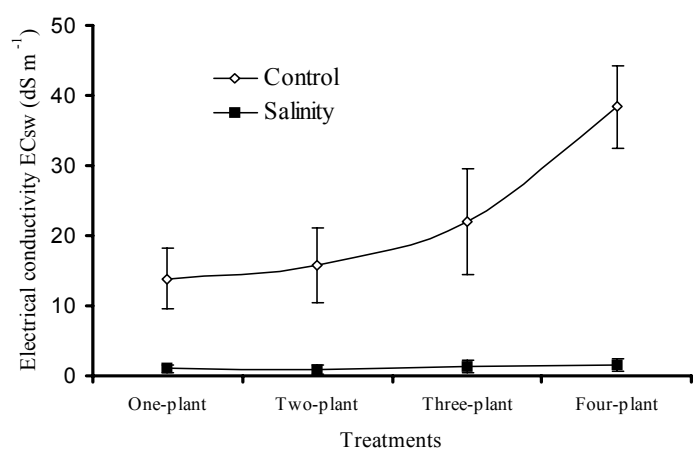

Fig. 4: Electrical conductivity at the harvesting time of different sorghum densities under two water qualities

\section{CONCLUSIONS}

The grain yield of different sorghum density, grown on dune sand and irrigated with 0.11 and $7.32 \mathrm{dS} \mathrm{m}^{-1}$ water, indicated that the crop was affected by plant density and water quality. Data indicate the stress indicator LWP varied temporally and variations depended on the water quality and crop density. In general, the mean of the temporal data for LWP was not sensitive to discriminate the impact of the input variables. In this regard PC20, median, and CV were found to be appropriate in that order. However, we recommend the use of $\mathrm{PC} 20$, as most appropriate indicators to characterize the impact of temporal dynamics of osmotic stresses. The PC20 has the advantage of being easily understood by laymen indicating that during about $20 \%$ of the growing period the crop was subjected to a given stress greater than a given value of the stress. We conclude the temporal sensitivity information in LWP is useful to assess the temporal risk associated with saline water irrigation, and stress water thereby to fine tune irrigation management options to reduce salinity and water stress risks. However, we highly recommend that each emitter should not plant more than one plant under saline condition.

\section{REFERENCES}

1. Ayers, R.S., and Westcot, D.W., 1985. Water quality for agriculture. FAO Irrigation and Drainage Paper 29, FAO, Rome.

2. Broughton R.S., 1995. Economic, production and environmental impacts of sub-irrigation and controlled drainage. In Sub-irrigation and Controlled Drainage, Belchard HW, D'ltri FM (eds). Lewish Publishers: Tokyo, pp: 482.
3. Fisher R.A., 1980. Influence of water stress on crop yield in semiarid regions. In: N.C. Turner and P.J. Kramer (Editors), Crop Water Requirements. Conf., 11-4 September 1984, Paris, INRA, Paris, pp. 221-234.

4. Gideon, O., DeMalach, Y., Gillerman, L., and David, I., 1995. Pear response to saline water application under subsurface drip irrigation. In Proceedings Fifth International Microirrgation Congress, Orlando, FL, April 2-6, pp. 97-103.

5. Gideon, O., DeMalach, Y., Gillerman, L., David, and I., Lurie, S., 2002. Effect of water salinity and irrigation technology on yield and quality of pears. Biosystems Eng. 81: 237-247.

6. Josserand, H., and Silva, A., 2002. Special report FAO/WFP crop and food supply assessment mission to Mauritania. 3 December, 2002. Homepage http://www.fao.org/documents/show_cdr.asp?url_fi le $=/$ docrep $/ 005 / \mathrm{y} 8163 \mathrm{e} / \mathrm{y} 8163 \mathrm{e} 00 . \mathrm{htm}$

7. Kamal, G.Y., and Hwat, B.S., 2001. The relationship between leaf water potential and stem diameter in Sorghum. Agron. J., 93: 1341- 1343.

8. Katerji N., J.W. van Hoorn, A. Hmdy, and M. Mastrorilli, 2003. Salinity effect on crop development and yield analysis of salt tolerance according to several classification methods. Agric. Water Manage. 62: 37-66.

9. Katerji N., J.W. van Hoorn, A. Hmdy, and M. Mastrorilli, 2004. Comparison of corn yield response to plant water stress caused by salinity and by drought. Agric. Water Manage. 65: 95-101.

10. Mastrorilli, M., Katerji, N., and Rana, G., 1995. Water efficiency and stress on grain sorghum at different reproductive stage. Agric. Water Manage.28: 23-34.

11. Ministère du développement rural, 1998. Raport de situation d'agrigulture. Nouakchott, Mauritania, pp. 4, unpublished.

12. Ould Ahmed, B.A., Yamamoto, T., Inoue, M., and Anyoji, H. 2006. Drip irrigation scheduling for sorghum under greenhouse condition. Trans. JSIDRE journal. Vol. 244, pp. 133-141.

13. Ould Ahmed, B.A., Yamamoto, T., Rasiah, V., Inoue, M., and Anyoji, H. 2007. The impact of saline water irrigation management options in a dune sand on available soil water and its salinity. Agricultural Water Management Journal. 88: 63 72. 
14. Pasternak, D., and DeMalach,Y., 1987. Saline water irrigation in the Negev Desert Paper presented at the Regional conference on Agriculture Food Production in the Middle-East, Athens, Greece, Jan. 21-26, pp. 24.

15. Rasiah V., .D. Armour, and A.L. Cogle, 2006. Statistical characterization of impact of system variables on temporal dynamics of groundwater in highly weathered regoliths. J. Hydrological Processes (in press).

16. Rees, D. J. 1989. The Effects of Population Density, Row Spacing and Intercropping on the Interception and Utilization of Solar Radiation by Sorghum bicolor and Vigna unguiculata in SemiArid Conditions in Botswana. J. Applied Ecology. 23: 917-928.

17. Rhoades, J.D., Kandiah, A., Mashali, A.M., 1992. The use of saline waters for crop production. FAO Irrigation and Drainage Paper No. 48, Rome, Italy.

18. Richard, G., Allen., Luis, S., Pereira., Dirk, R., and Martin, S., 1998: Water resources, development and management service FAO No 56. pp.161-182

19. Santos F.A.P., Huber, J.T., Theurer, C.B., Swingle, R.S., Wu, Z., Simas, J.M., Chen, K.H., Chan, S.C., Santos, j., and Depeters, E.J. 1997. Comparison of barley and sorghum grain processed at different densities for lactating dairy cows. J. Dairy Sci.; 80: 2098-2103.
20. Shalhevet, J., 1991. Using water of marginal quality for crop production: major issues. In: J. Shalhevet, L. Cangmimg and X. Yuexian 9Editors), Water use efficiency in agriculture. Proceedings of the binational China-Israel workshop, Beijing, China. Peril publ. Rehovot, Israel, pp. 17-53.

21. Shalhevet, J., 1994. Using water of marginal quality for crop production: major issues. Agric. Water Manage. 25: 233-269.

22. Shani U., and L.M. Dudley, 2001. Field studies of crop response to water and salt stress. Soil Sci. Soc. Am. J. 65: 1522-1528.

23. Van Dam J.C., 2000. Field scale water flow and solute transport. SWAP model concept, parameter estimation, and case studies. Ph.D thesis. Wageningen University, Wageningen.

24. Van Ek, R., Witte, JPM., Runhaar, H., and Klijn, F., 2000. Ecological effects of water management in the Netherlands: the model DEMNAT. Ecological Engineering 16: 127-141.

25. Watkinson, A.R., Lonsdale, W.M., and Andrew, M.H., 1989. Modelling the Population Dynamics of an Annual Plant Sorghum Intrans in the WetDry Tropics. J. Ecological., 77: 162-181. 